This item was submitted to Loughborough's Research Repository by the author.

Items in Figshare are protected by copyright, with all rights reserved, unless otherwise indicated.

\title{
Predicting the performance of pressure filters
}

PLEASE CITE THE PUBLISHED VERSION

PUBLISHER

(C) Elsevier

VERSION

AM (Accepted Manuscript)

LICENCE

CC BY-NC-ND 4.0

REPOSITORY RECORD

Tarleton, E.S.. 2009. "Predicting the Performance of Pressure Filters". figshare. https://hdl.handle.net/2134/4915. 
This item was submitted to Loughborough's Institutional Repository (https://dspace.lboro.ac.uk/) by the author and is made available under the following Creative Commons Licence conditions.

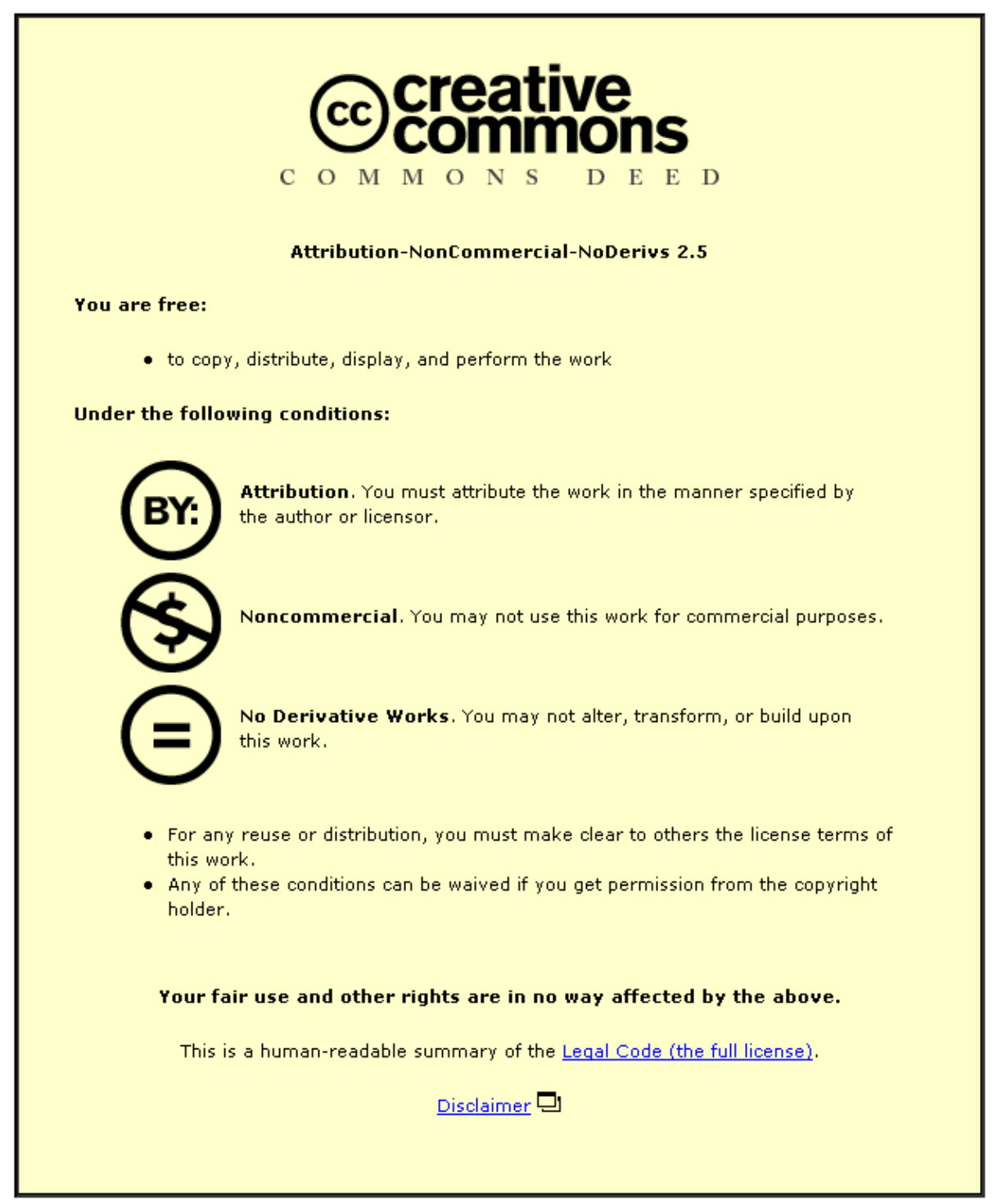

For the full text of this licence, please go to: http://creativecommons.org/licenses/by-nc-nd/2.5/ 


\title{
PREDICTING THE PERFORMANCE OF PRESSURE FILTERS
}

\author{
E.S. Tarleton (e.s.tarleton@lboro.ac.uk) \\ Department of Chemical Engineering, Loughborough University, Loughborough, Leics., LE11 3TU, \\ UK.
}

\section{SUMMARY}

As a step towards removing heuristics from the design and specification of filters it is shown how accurate experimentation and modelling can be utilised to predict the performance of a pressure leaf filter over a range of experimental conditions. An experimental apparatus combining the principles of mechatronics with a deadend pressure leaf filter is outlined along with sample data which outline its versatility. Experimental data obtained from the apparatus are compared with predictions given by classical filtration theories incorporated within flexible computer simulations. Batch experimental results obtained at constant pressure with aqueous suspensions of calcite, talc and zinc sulphide are shown to match well with theoretical predictions of the important design parameters cake height and cumulative volume of filtrate, particularly when cake compressibility is lower. Constant pressure data are further used to predict constant flow filtrations where the applied pressure is manipulated via computer software.

\section{INTRODUCTION}

For many years now separations technologists have attempted to understand and predict filtration performance. Some have chosen to pursue experimental routes with a range of suspensions and methodologies whereas others have preferred to develop simulations of filter performance, often through comparisons with experimental data ${ }^{1-17}$. The fact that we are still heavily reliant on heuristics or 'rules-of-thumb' for the design and specification of separation devices ${ }^{18}$ indicates the difficulties which researchers have encountered in predicting the complex, transient behaviour of solid/liquid mixtures. Eliminating the need for heuristics would preclude the need to perform many costly experiments when specifying larger scale filters and save both time and investment.

Of interest in this paper is cake filtration which relies on the preferential entrapment of particulates on a semi-permeable medium under the action of an imposed pressure gradient. The filter medium is relatively thin and provides the separating surface only at the initial stage(s) of filtration, after which it acts primarily as support to the growing, frequently compressible cake. The relationship between the filtrate flow rate, the applied pressure $(\Delta p)$ and the filter cake properties is classically expressed through a modified form of Darcy's law ${ }^{14}$ which for filtration at constant pressure/variable flow may be written as

$$
t_{f}=\frac{\alpha_{a v} \mu \rho M_{s}}{2 A^{2} \Delta p\left(1-M_{s}\left(1+e_{a v}\left(\rho / \rho_{s}\right)\right)\right)} V_{f}^{2}+\frac{\mu R_{m}}{A \Delta p} V_{f}
$$

and at conditions of constant flow/variable pressure may be written as

$$
t_{f}=\frac{A^{2}\left(1-M_{s}\left(1+e_{a v}\left(\rho / \rho_{s}\right)\right)\right)}{\alpha_{a v} \mu \rho M_{s} Q^{2}}\left(\Delta p-\mu R_{m} \frac{Q}{A}\right)
$$

where $V_{f}$ is the cumulative volume of filtrate, $t_{f}$ the filtration time, $e_{a v}$ the average cake voids ratio, $\alpha_{a v}$ the average specific cake resistance, $A$ the filter area, $\mu$ the filtrate dynamic viscosity, $M_{s}$ the solids mass fraction in the feed, $\rho$ the filtrate density, $\rho_{s}$ the solids density, $R_{m}$ the filter medium 
resistance and $Q$ the filtrate flow rate. In both cases the filter cake height $(h)$ as a function of time is given by

$$
h=\frac{V_{f}\left(1+e_{a v}\right)}{A\left(\frac{\rho_{s}}{\rho}\left(\frac{1}{M_{s}}-1\right)-e_{a v}\right)}
$$

The average specific cake resistance $\left(\alpha_{a v}\right)$ and cake voids ratio $\left(e_{a v}\right)$ are classically determined through sequences of constant pressure filtration tests to give the four empirically derived scale-up constants $\alpha_{0}, n, e_{0} \& b_{1}$ whereby

$$
\begin{aligned}
& \alpha_{a v}=\alpha_{0}(1-n) \Delta p_{c}^{n} \\
& e_{a v}=e_{0}-b_{1} \log \left(\Delta p_{c}\right)
\end{aligned}
$$

and $\Delta p_{c}$ is the pressure gradient across the cake. The combination of eqns. (1)-(5) allows filtration performance to be evaluated when process conditions and the values of the scale-up constants are known. Thus, flexible computer simulations incorporating eqns. (1)-(5) have been written (as an extension of some of the authors previous work ${ }^{14,19}$ ) to allow for the prediction of important design parameters such as cumulative volume of filtrate and cake height. In the following, predictions are compared with batch experimental data obtained using a leaf filter at conditions of constant pressure and constant flow and a discussion of the results presented.

\section{EXPERIMENTAL APPARATUS AND PROCEDURES}

To facilitate comparisons between theoretical predictions and experimental data over a range of pressure/flow regimes it was necessary to characterise feed suspensions and determine both cake growth and filtrate flow rates continuously during a filtration test.

The characterisation tests were performed using standard laboratory equipment including that commercially available from Malvern Instruments ${ }^{\mathrm{TM}}$ and Coulter Electronics ${ }^{\mathrm{TM}}$. To establish a range of suspension and cake properties for the subsequent filtration tests calcite, zinc sulphide and talc powders dispersed in distilled water were characterised in terms of particle size distribution, particle shape and surface charge (through zeta $(\zeta)$-potential). The $0.2 \mu \mathrm{m}$ rated Gelman Versapor membranes chosen as filter media were characterised in terms of pore size distribution, thickness and permeability. The pertinent characterisation data are shown in Table 1. The particle systems were chosen for their different natures, the ability to characterise properties and their representation of 'real' suspensions with size distribution whilst the membrane was chosen to promote cake filtration.

The experimental apparatus used to determine the filtration properties of the test suspensions has been partly described in detail previously ${ }^{20,21}$. The fully automated and computer driven apparatus comprised of a stirred feed vessel and an $80 \mathrm{~cm}^{2}$ deadend pressure leaf filter containing 256 electrode probes arranged in sixteen horizontal rings throughout the height of the filter cell. By switching electrode pairs through dedicated electronic circuitry the cake structure, cake saturation and cake height at any given time could be determined. All sequencing of the apparatus and data acquisition were performed by the computer in a consistent manner at test pressures up to 600 $\mathrm{kPa}$ to allow for the tracking of a filter cycle.

The pressures required to progress the filtrations were provided by the combination of a dedicated compressor and a computer driven electronic pressure regulator. Whilst constant pressure 
filtrations were relatively simple to perform those maintained at conditions of constant filtrate flow required continual adjustment of the filtration pressure to an extent dependent on the nature of the process suspension and the desired process conditions. Filtrate flows were monitored via successive timed readings from an electronic balance interfaced to the computer. The flow rate readings were interpreted by an appropriate control algorithm and the filtration pressure adjusted according to the controller settings and the current flow offset. For the purpose of this paper a negative feedback control action proportional to the flow offset (or error) was used to maintain constant flow rate conditions such that

$$
\text { controller output }=K_{p} E
$$

where $K_{p}$ is the proportional gain and $E$ is the offset between the flow set point and the measured filtrate flow rate. When a deviation from the desired flow conditions was measured the controller would attempt to drive the offset to zero by changing the applied pressure to compensate.

\section{EXPERIMENTAL RESULTS AND DISCUSSION}

In order to establish predictive models for cake formation at constant, or indeed variable, pressure it is a prerequisite to be able to generate reliable and repeatable experimental data. Whilst the latter have been demonstrated previously by the author ${ }^{21}$, and some further examples are shown in Figures 1-4, it is also necessary to be able to predict parameters such as cumulative volume of filtrate and cake growth rate as functions of time. The experimental data and model predictions shown in Figures 4-11 demonstrate how data sequences can be generated and reasonably predicted for a range of suspensions when the scale-up constants in eqns. (4) \& (5) are known. To determine values for the empirical constants it is conventional practice ${ }^{22}$ to perform series' of constant pressure experiments and this was done for calcite and talc suspensions over the pressure range $50-600 \mathrm{kPa}$ using the apparatus described (denoted as Apparatus 1). Further constant pressure experimental data from a completely separate apparatus (denoted Apparatus 2) were also available for calcite and zinc sulphide suspensions at feed concentrations up to $20 \% \mathrm{v} / \mathrm{v}$. This apparatus was also computer controlled and employed a filter cell of area $22.8 \mathrm{~cm}^{2}$ incorporating 32 pairs of electrodes arranged in a single vertical plane. Table 2 shows a summary of the empirical constants obtained through consistent analysis procedures from the two apparatus' and indicates the incompressible nature of the calcite filter cakes and the moderately compressible nature of the talc and zinc sulphide cakes ${ }^{23}$.

Figure 1 illustrates data for five experiments using calcite suspensions where cake formations proceeded at constant pressures of $300 \mathrm{kPa}$. The repeatable nature of the experiments and apparatus is apparent from these data and confirmed by the sequential nature of the data for talc suspensions shown in Figure 2. Here a raised test pressure showed a correspondingly reduced gradient on the $t / V$ vs. $V$ plot. For the sample data presented linear regressions yielded coefficients of determination in excess of 0.99 and showed $\alpha_{a v}$ to vary between $4.3 \times 10^{10} \& 1.9 \times 10^{11}$ $\mathrm{m} \mathrm{kg}^{-1}$ with $R_{m}$ varying between $3.8 \times 10^{10}$ and $3.0 \times 10^{11} \mathrm{~m}^{-1}$ over the pressure range $50-600 \mathrm{kPa}$. The compressible nature of the talc system is highlighted by the range of values for $\alpha_{a v}$ whilst the variations in $R_{m}$ are due to a degree of filter medium compression ${ }^{23}$.

By switching series' of diametrically opposed electrode pairs within the filter cell, transient solids concentration profiles could be measured throughout cake formation. Figure 3 shows a typical example for two calcite suspensions at feed concentrations of $10 \& 20 \% \mathrm{v} / \mathrm{v}$ respectively and a zinc sulphide suspension at a concentration of $10 \% \mathrm{v} / \mathrm{v}$. For the relatively incompressible calcite system a $20 \% \mathrm{v} / \mathrm{v}$ suspension formed a thicker cake than a $10 \% \mathrm{v} / \mathrm{v}$ suspension in a given time (as expected) with the measured cake concentrations remaining essentially constant throughout a given test. For more compressible systems such as zinc sulphide a wider range of concentrations were typically seen through a filtering cake and these concentrations would typically increase as filtration progressed. The accuracy of such data were appropriately confirmed by mass sampling 
and the form of a transient solids concentration profile gave a good indication of the cake compressibility and the particle rearrangement induced by the flow of liquid through cake interstices.

Figure 4 shows an example where proportional control of the filtration apparatus has been employed in order to maintain a constant filtrate flow and setpoint of $5 \times 10^{-7} \mathrm{~m}^{3} \mathrm{~s}^{-1}$ (equivalent to a flux of $2.2 \times 10^{-4} \mathrm{~m}^{3} \mathrm{~m}^{2} \mathrm{~s}^{-1}$ ). The behaviour is typical of proportional control whereby the overshoot response observed toward the start of filtration is followed by a decaying oscillatory response; the latter resulting in a near constant filtrate flow with a fixed offset from the setpoint. During the constant rate period the filtration pressure is seen to rise in an essentially linear manner in accordance with eqn. (2) until the maximum allowed pressure is reached. At this point constant pressure filtration commences and the filtrate flow rate is seen to decay in the expected manner until the end of the test. Although few similar data are currently available, it is clear from Figure 4 that with computer control the facility exists for constant pressure, constant flow and variable pressure/flow tests to be performed within one experimental apparatus. Suspensions can be introduced to a filter in a consistent manner and, through appropriate control of the delivery pressure and flow monitoring, filtrations performed to mimic pumping operations with both positive displacement and centrifugal pumps.

Figures 5-7 show cumulative volume of filtrate vs. time data for constant pressure filtrations involving calcite, talc and zinc sulphide suspensions respectively. The progressive changes in the data as pressures are raised are self evident and these again highlight the benefit of being able to perform experiments in an automated manner. Also shown on these plots are theoretical predictions of filtrate volume vs. time as given by the simulation based on eqn. (1) and the scale-up constants incorporated in eqns. (4) \& (5). The excellence of the predictions, particularly for calcite and talc, are indicative of the accuracy of the simulation when incompressible and moderately compressible systems which sediment at a relatively low rate are considered. The data for calcite are particularly significant as the values for the empirical constants $\alpha_{0}, n, e_{0} \& b_{1}$ employed in the simulations were determined from Apparatus 2 and used to predict the performance of Apparatus 1. When predictions of filtrate volume with time were made for suspensions which settle at an appreciable rate, deviations were observed from experimental values. The data for zinc sulphide shown in Figure 7 were typical whereby predicted values fell below the corresponding experimental values by up to $10 \%$. Such a situation would yield a potentially oversized filter if the simulation was used in predictive scale-up calculations. It is not unusual for the settling of coarser particulates to improve separation rates in downward filtrations and the situation frequently presents difficulties when scale-up calculations are required ${ }^{24}$. Several authors have attempted to address the problems of combined sedimentation and filtration ${ }^{25-27}$, though clearly more work is required to reconcile the problems which exist.

As a consequence of measuring solids concentration profiles in the filter cell it was possible to evaluate changes in filter cake height with time. For calcite experiments it was relatively easy to determine the position of the filter cake surface as the solids concentration would change very rapidly during the transition from suspension to cake. With talc and zinc sulphide, however, it was more difficult to identify the transition and an approximation was made whereby cake was assumed to exist at concentrations of $30 \% \mathrm{v} / \mathrm{v}$ or more. Figures $8-10$ respectively show cake thickness vs. time data for calcite, talc and zinc sulphide suspensions filtered at a range of pressures between $100 \& 600 \mathrm{kPa}$. As expected, cakes were formed more rapidly at the higher filtration pressures and data were invariably sequential as pressure was raised. Through combinations of eqns. (3)(5) predictions could be made of cake growth with time.

Figure 8 shows typical comparisons between predicted and experimentally determined cake growths during the filtration of calcite suspensions at three different pressures. The excellence of the fit is once more indicative of the accuracy of the simulation when essentially incompressible systems, such as calcite, are considered and it is again noted that the predictions were performed using scale-up data obtained from a different apparatus. The data shown in Figures $9 \& 10$ for talc 
and zinc sulphide suspensions respectively indicate that despite the careful control of filtration the theoretical predictions of cake height are relatively poor. Earlier it was stated that with the compressible nature of talc it is difficult to identify the position of the interface between the cake and the filtering suspension and a somewhat arbitrary value of $30 \% \mathrm{v} / \mathrm{v}$ was chosen to be a minimum concentration for cake to exist. Assuming that the experimental data are accurate it must be concluded that either an incorrect value for the minimum cake concentration was chosen or the model used in the simulation is flawed. The data at the lower pressure suggest that a concentration higher than $30 \% \mathrm{v} / \mathrm{v}$ should be chosen to identify the presence of cake as this would improve the fit between the model and the experimental data. On the contrary, the data at the higher pressure suggest that choosing a lower concentration may be more appropriate. This apparent anomaly is difficult to reconcile, though the concentrations measured in the talc experiments were typically below $40 \% \mathrm{v} / \mathrm{v}$ and they strongly indicate that a solids concentration of $30 \% \mathrm{v} / \mathrm{v}$ should be considered as cake.

In Figure 4 (and previously ${ }^{28}$ ) it was shown how air pressure could be manipulated by computer software to allow for constant flow filtration. In Figure 11 the same filtration pressure vs. time data are reproduced and compared with predictions made using eqn. (2) and the four scale-up constants in eqns. (4) \& (5) derived from sequences of constant pressure tests. The predicted changes in pressure with time are reasonably close to the experimentally measured values, particularly when a filter medium resistance toward the lower end of the range calculated from the filtration experiments was used in the simulation ${ }^{\dagger}$. It is probably premature to draw any definitive conclusions from Figure 11 as relatively few similar data have been produced to date, however, it is interesting to compare the experimental approach of the author with that taken by previous workers. Several researchers have attempted to perform filtration experiments at conditions of constant flow and variable pressure/variable flow by utilising:

a. A positive displacement/centrifugal pumping device, which both Harvey et al. ${ }^{29}$ and Tiller $^{30}$ have correctly noted can easily change suspension characteristics due to the presence of relatively large shear forces.

b. The manual adjustment of pressure, which requires considerable operator skill and dexterity, particularly when filtration conditions are changing quickly ${ }^{30-32}$.

c. A piston press ${ }^{33}$, a device which is well known to experience wall effect problems.

Although methodologies (a)-(c) have been employed to produce viable experimental data there are inherent problems with each which are difficult to reconcile with confidence. Whilst the approach taken in this paper is still at an early stage of development, there are several potential advantages in utilising a single, fully automated, computer controlled, apparatus where filtration pressure is manipulated via suitable algorithms and instrumentation. Experiments can be performed in a repeatable manner under different pressure/flow regimes to mimic the operation of industrial filtrations using positive displacement and centrifugal pumps. Separations can performed by any chosen pressure/flow regime without changing the properties of the feed in an inappropriate, and un-quantifiable, manner. The characterising parameters for each mode of filtration can be determined under well controlled, dynamic conditions, without resorting to sequences of essentially static experiments. Moreover, these parameters can be directly compared with a degree of confidence and the inter-relations which exist thus determined.

\section{CONCLUSIONS}

Cake filtration has previously attracted a great deal of academic interest due to its widespread use throughout the chemical and process industries. Whilst much of the work performed has undoubtedly progressed our understanding, the majority has utilised what must now be considered

\footnotetext{
${ }^{\dagger}$ It is noted in passing that filter medium resistances of $2.9 \times 10^{10} \mathrm{~m}^{-1}$ and $2.6 \times 10^{10} \mathrm{~m}^{-1}$ were quoted
} by the manufacturer and measured in water permeation tests respectively. 
relatively elementary experimental equipment and been restricted largely to constant pressure investigations. Such research methodologies are limited in several ways. By their natures filtrations are transient processes, usually involving changes in cake properties with time. The resultant need to adjust operational parameters to maintain chosen experimental conditions necessitates outside interference unless appropriate controllers and monitoring equipment are used. Potentially variable operator interference has plagued filtration research over the years with the result that experimental data have often been unreliable and difficult to obtain quickly. Whilst it is relatively easy to perform constant pressure filtrations in the laboratory it is not always employed in industrial scale filtrations. Here, it is perhaps more normal to positive displacement or centrifugally pump suspensions into filter chambers and perform filtrations according to the pressure \& flow characteristics of the pumping device. The recommended practice of employing series' of constant pressure filtrations to represent other pressure/flow filtration regimes is based on the assumption that sequences of essentially 'static' tests can be employed to represent more 'dynamic' processes. There is minimal proof that this assumption is correct. Indeed the problems faced by industry in translating constant pressure data are well known by experts, if not always well documented in publications and there is much reliance on heuristics.

The ability to generate reliable experimental data is a prerequisite to understanding filtration processes. With the advent of mechatronics technologists now have the opportunity to both examine filtration processes in new, novel and more accurate ways and remove the heuristics from the design and specification of filters. In this paper it has been shown how mechatronic principles can be utilised to provide automated and repeatable experiments over a range of filtration conditions and feed materials without changing the characteristics of feed suspensions. It has also been shown how flexible computer simulations can predict separation performance when constant pressure and constant flow regimes are used and reliable scale-up parameters are available. Although some comparisons of constant pressure and constant flow filtrations have been presented to show the principles of what can be achieved, more work is required before significant conclusions can be drawn. The correct combinations of hardware, software and control philosophies need to be developed to manipulate pressures and/or flows accurately over wide ranges in reliable and repeatable manners. With these in place it should prove possible to quantify filtration characteristics in better forms than the series' of static constant pressure tests currently used, thus allowing for more accurate scale-up methodologies and less reliance on heuristics.

\section{ACKNOWLEDGEMENT}

The author would like to acknowledge the financial support of the Engineering and Physical Science Research Council for part of the research presented in this paper.

\section{NOMENCLATURE}

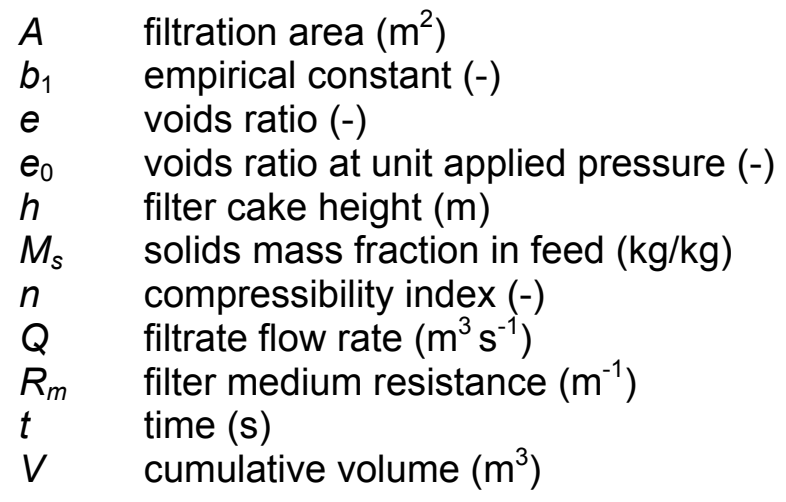

Greek symbols 
$\alpha \quad$ specific cake resistance $\left(\mathrm{m} \mathrm{kg}^{-1}\right)$

$\alpha_{0} \quad$ specific cake resistance at unit applied pressure $\left(\mathrm{m} \mathrm{kg}^{-1} \mathrm{~Pa}^{-n}\right)$

$\Delta p \quad$ applied pressure $(\mathrm{Pa})$

$\mu \quad$ filtrate dynamic viscosity (Pa s)

$\rho \quad$ filtrate density $\left(\mathrm{kg} \mathrm{m}^{-3}\right)$

$\rho_{s} \quad$ solids density $\left(\mathrm{kg} \mathrm{m}^{-3}\right)$

Subscripts

c cake

$f \quad$ filtration phase

Superscripts

av average value

\section{REFERENCES}

1. Grace H.P, Resistance and compressibility of filter cakes (Part 1), CEP, 49(6), 303, 1953.

2. Grace H.P., Resistance and compressibility of filter cakes (Part 2), CEP, 49(7), 367, 1953.

3. Tiller F.M., Solid-Liquid Separation, University of Houston, Houston, 1975.

4. Shirato M., Sambuichi M., Murase T., Aragaki T., Kobayashi K. and Iritani E., Theoretical and experimental studies in cake filtration, Mem. Fac. Eng. Nagoya Uni., 37(1), 38, 1985.

5. Willis M.S., Collins R.M. and Bridges W.G., Complete analysis of non-parabolic filtration behaviour, Chem. Eng. Res. Des., 61, 96, 1983.

6. Stahl W. and Nicolaou I., Calculation of rotary vacuum plant, Industrie Minerale Mines et Carrieres Les Techniques, 3/91, 14, 1991.

7. Kobayashi Y., Ohba S. and Shimuzu K., Analysis of dewatering performance of belt filter press, Proc. $6^{\text {th }}$ World Filtration Congress, pp.778-781, Japanese Filtration Society, Nagoya, 1993.

8. Nystrom L.H.E., Simulation of disc filter for the pulp and paper industries, Filt. and Sep., 30(6), 554, 1993.

9. Wakeman R.J. and Wei X., Simulating the performance of tilting pan filters, Filt. and Sep., 32(10), 979, 1995.

10. Kottwitz F.A. and Baylan D.R., Prediction of resistance in constant pressure cake filtration, AlChEJ, 4(2), 175, 1958.

11. Risbud H.M., Cake filtration empirically incorporating particle migration, Filt. and Sep., 18(1), 20, 1981.

12. Silverblatt C.E., Risbud H. and Tiller F.M., Batch, continuous processes for cake filtration, Chem. Engng., April, 127, 1974.

13. Stamatakis K. and Tien C., Cake formation and growth in cake filtration, Chem. Eng. Sci., 46(8), 1917, 1991. 
14. Wakeman R.J. and Tarleton E.S., A framework methodology for the simulation and sizing of diaphragm filter presses, Min. Eng., 7(11), 1411, 1994.

15. Carleton A.J. and Mehta K.B., Leaf test predictions and full-scale performance of vacuum filters, Filt. and Sep., Jan/Feb, 55, 1984.

16. Fitzgibbons D.P., Filtration rates of rotary vacuum filters, Filt. and Sep., May/June, 227, 1976.

17. Wu Y., An analysis of constant pressure filtration, Chem. Eng. Sci., 49(6), 831, 1994.

18. Purchas D.B. and Wakeman R.J., Solid/Liquid Separation Equipment Scale-up (2 ${ }^{\text {nd }}$ Edn.), pp.701-744, Uplands Press, London, 1986.

19. Wakeman R.J. and Tarleton E.S., Simulation and process design of the filter cycle, Filt. and Sep., 27(6), 412, 1990.

20. Tarleton E.S. and Hancock D.L., The imaging of filter cakes through electrical impedance tomography, Filt. and Sep., 33(6), 491, 1996.

21. Tarleton E.S. and Hancock D.L., Using mechatronics for the interpretation and modelling of the pressure filter cycle, Trans. IChemE, 75(A), 298, 1997.

22. Wakeman R.J., Thickening and filtration: A review and evaluation of recent research, Trans. IChemE, 59(A), 147, 1981.

23. Tarleton E.S. and Willmer S.A., The effects of scale and process parameters in cake filtration, Trans. IChemE, 75(A), 497-507, 1997.

24. Purchas D.B. and Wakeman R.J., Solid/Liquid Separation Equipment Scale-up (2 ${ }^{\text {nd }}$ Edn.), pp.428, Uplands Press, London, 1986.

25. Bockstal F., Fourage L., Hermia J. and Rahier G., Constant pressure cake filtration with simultaneous sedimentation, Filt. and Sep., 22(4), 255, 1985.

26. Clarke J.W., Kimber G.M. and Rantell T.D., Influence of particle sedimentation on filtration, CEP, 88, 55, 1981.

27. Tiller F.M., Hsyung Y.L. and Shen Y.L., Catscan analysis of sedimentation and constant pressure filtration, Proc. $5^{\text {th }}$ World Filtration Congress, pp.80-85, Societe Francaise de Filtration, Nice, 1990.

28. Tarleton E.S., A mechatronics approach to solid-liquid separation, Proc. $7^{\text {th }}$ World Filtration Congress, pp.311-315, Hungarian Chemical Society, Budapest, 1996.

29. Harvey M.A., Bridger K. and Tiller F.M., Apparatus for studying incompressible and moderately compressible cake filtration, Filt. and Sep., Jan/Feb, 21, 1986.

30. Tiller F.M., The role of porosity in filtration Part 3: Variable-pressure variable-rate filtration, AIChEJ, 4(2) , 170, 1958.

31. Shirato M., Aragaki T., Iritani E. and Funahashi T., Constant rate and variable pressure variable rate filtration of power-law non-Newtonian fluids, J. Chem. Eng. Japan, 13(6), 473, 1980. 
32. Shirato M. and Aragaki T., Verification of internal flow mechanism theory of cake filtration, Filt. and Sep., MaylJune, 290, 1972.

33. Murase T., Iritani E., Hattori M., Kobayashi K. and Shirato M., Variable-pressure filtration of power-law non-Newtonian fluids on cylindrical surfaces, J. Chem. Eng. Japan, 20(6), 632, 1987. 


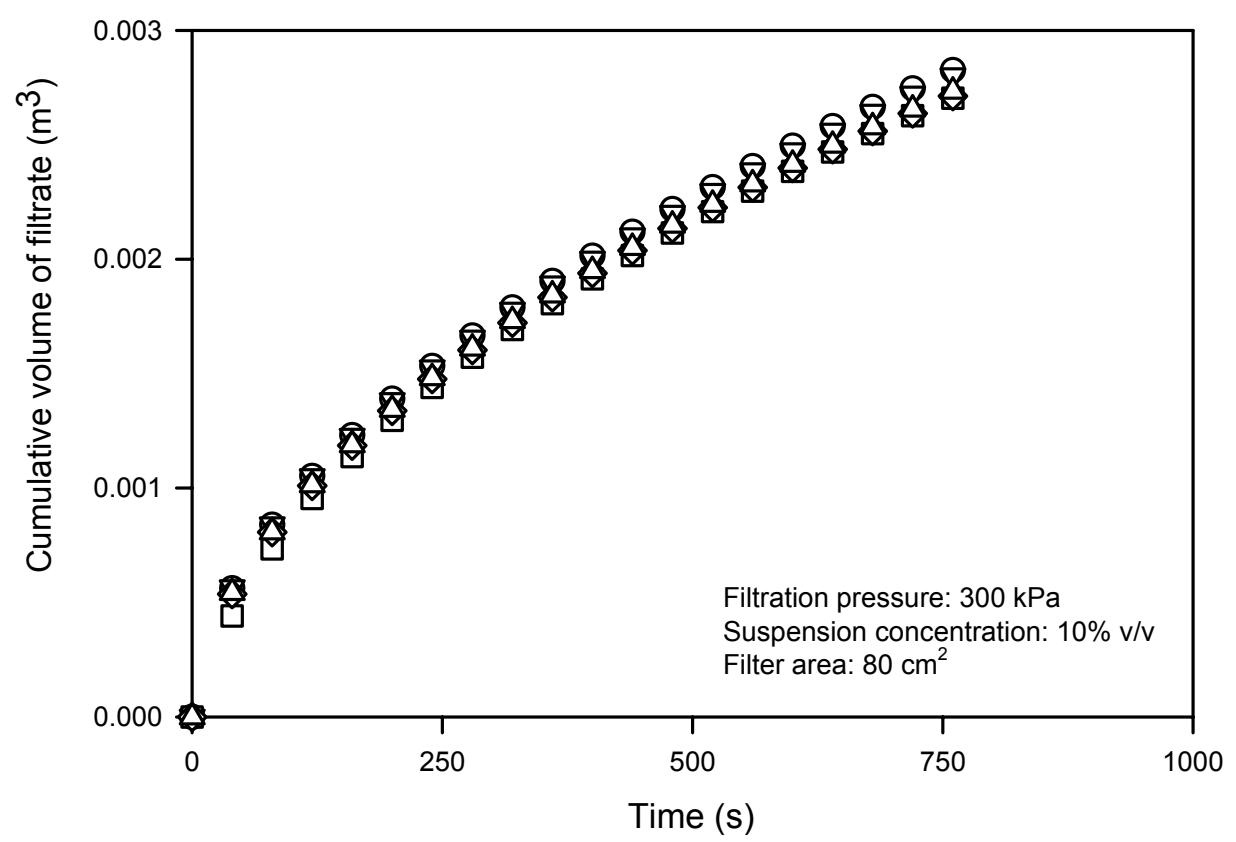

Figure 1: Filtration data sequences for $10 \%$ v/v calcite suspensions.

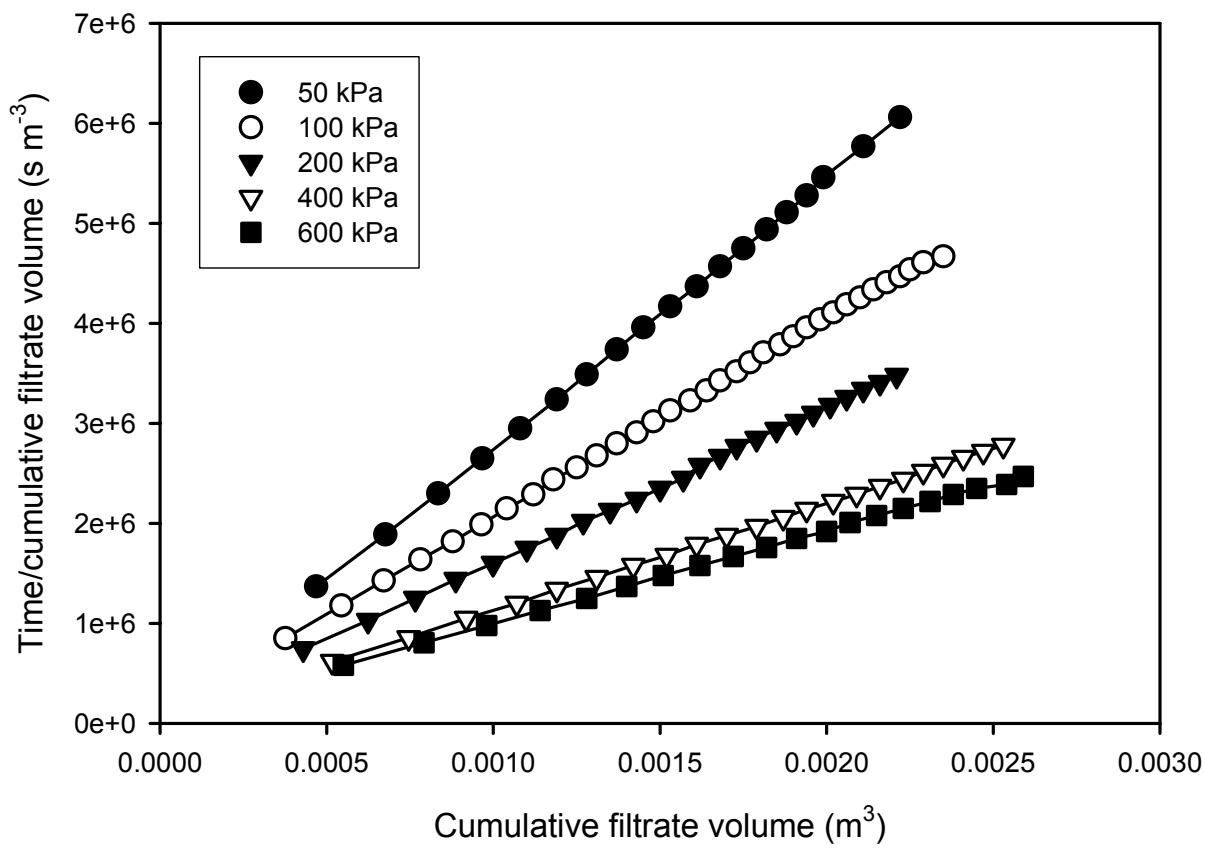

Figure 2: The effect of pressure on the filtration of $10 \% \mathrm{v} / \mathrm{v}$ talc suspensions. 


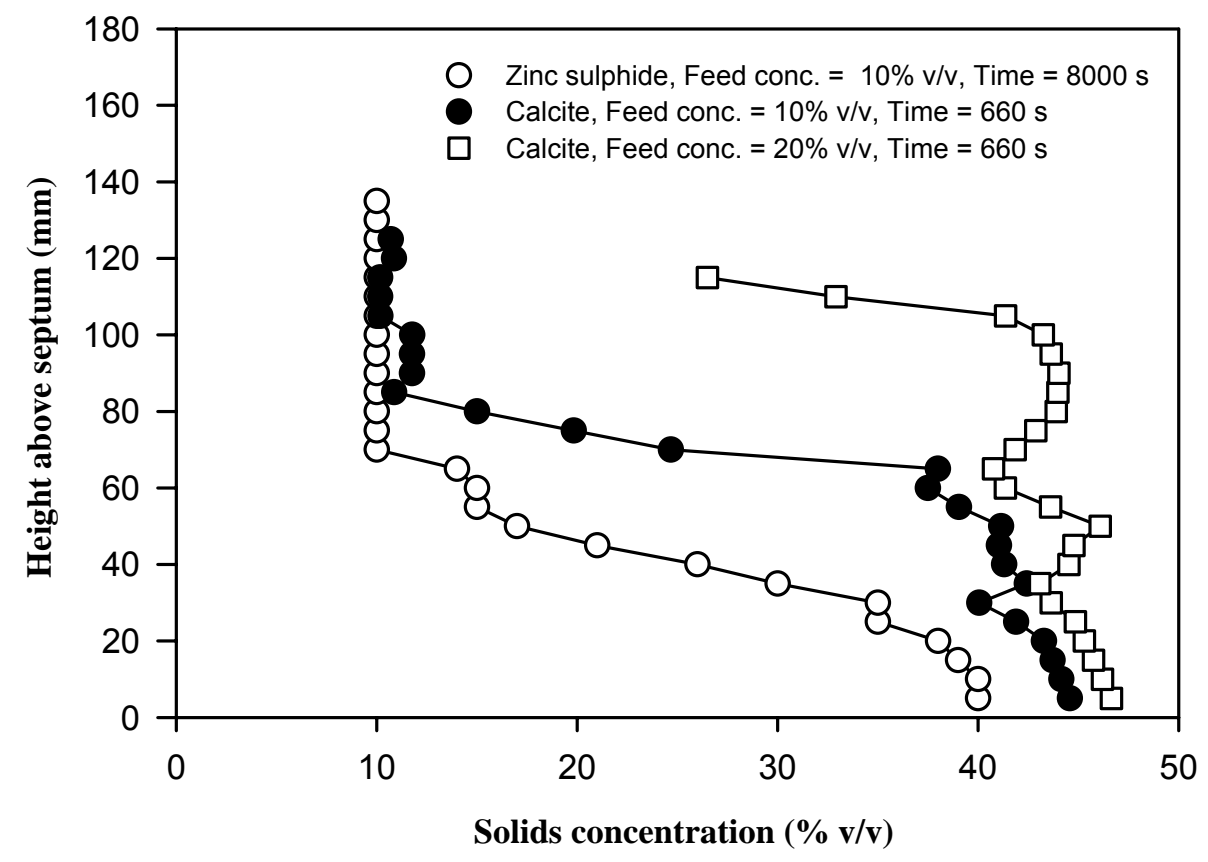

Figure 3: Typical solids concentration profiles during the constant pressure filtration of calcite and zinc sulphide suspensions at $100 \mathrm{kPa}$.

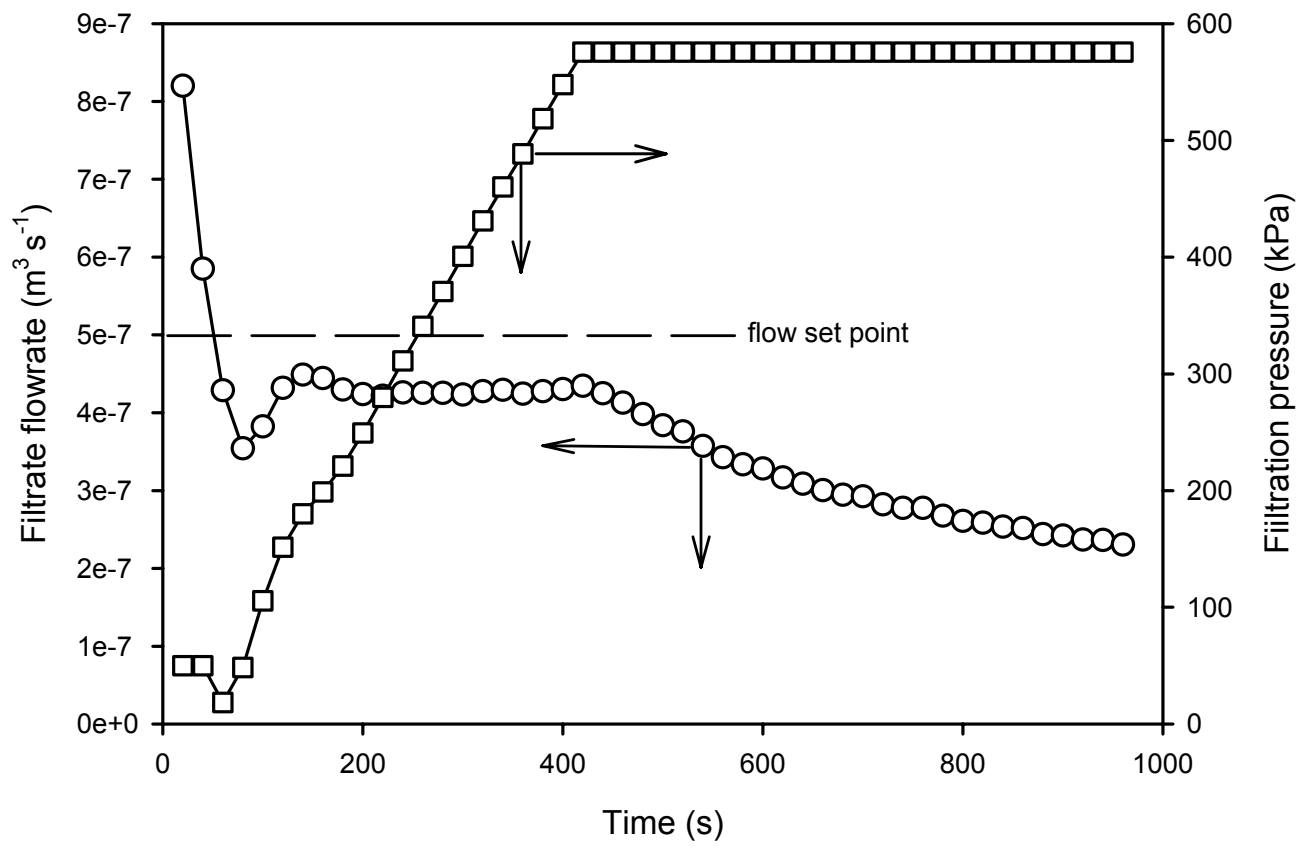

Figure 4: Typical pressure and filtrate flow rate histories for the proportionally controlled filtration of a suspension forming an incompressible cake. 


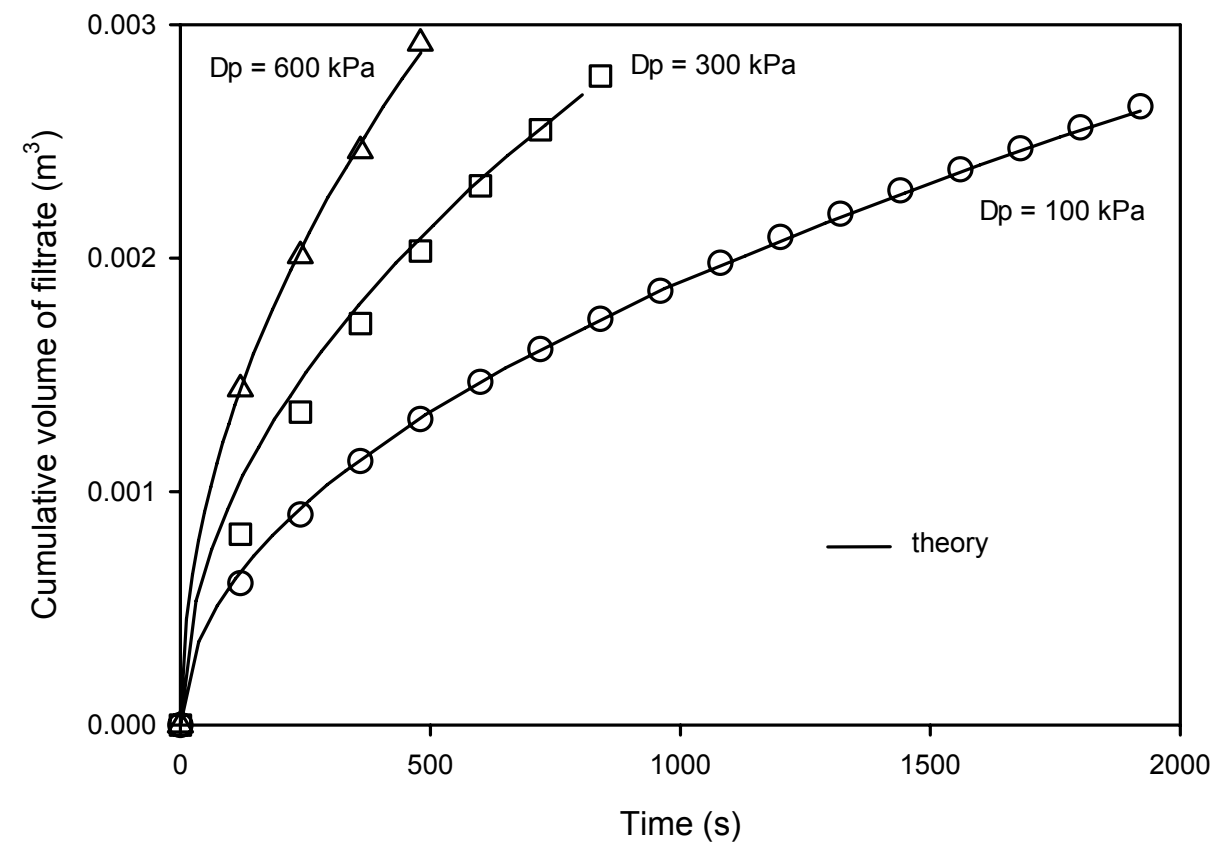

Figure 5: Comparisons of experimental and predicted data for calcite filtrations at constant pressures.

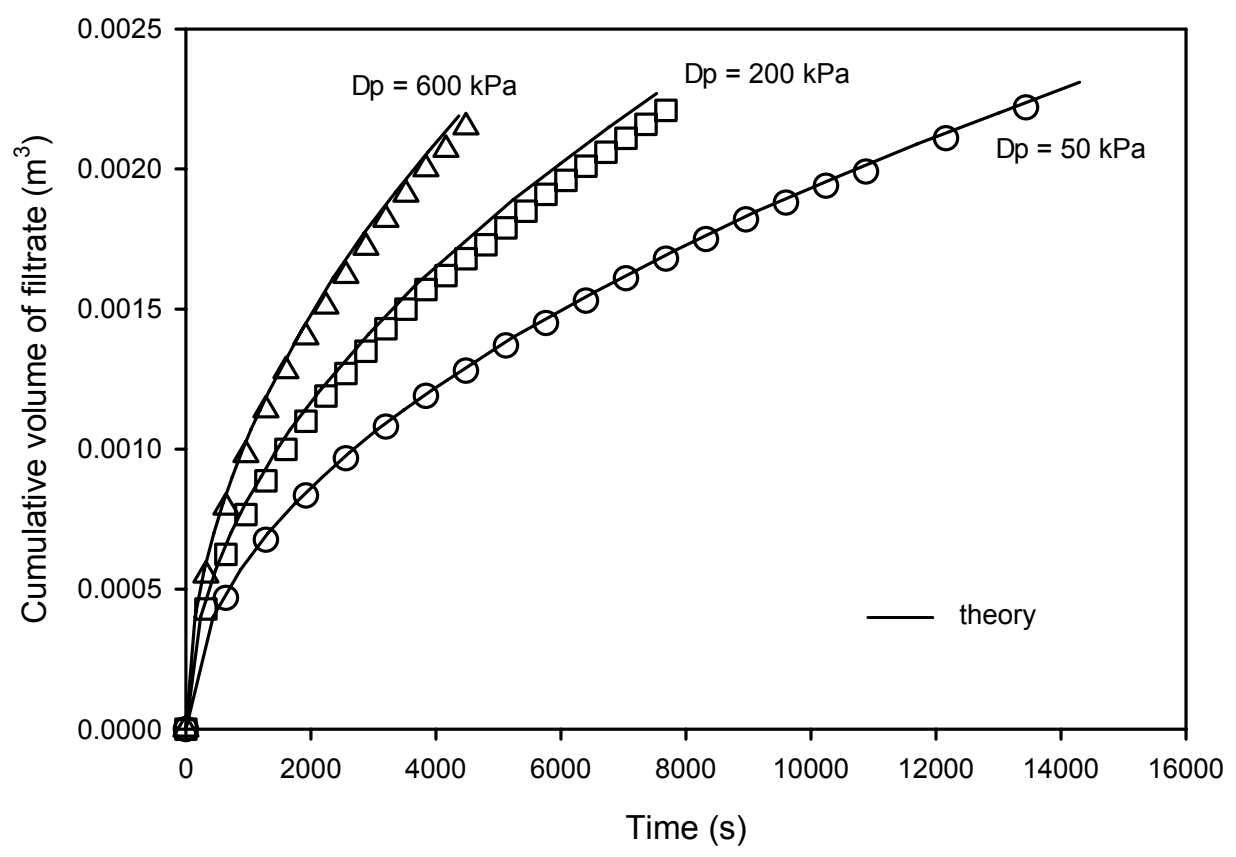

Figure 6: Predictions of volume of filtrate vs. time for the constant pressure filtration of talc suspensions. 


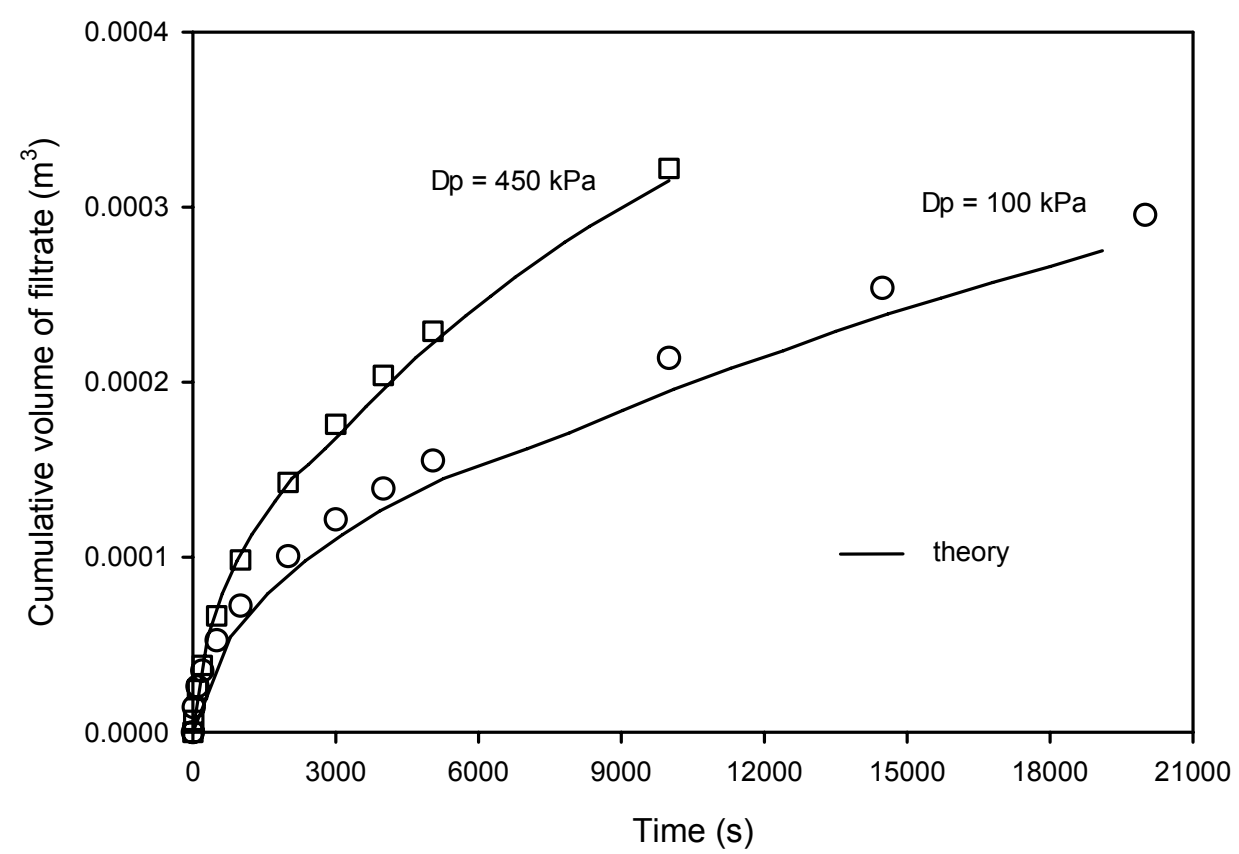

Figure 7: Predictions of volume of filtrate vs. time for the constant pressure filtration of zinc sulphide suspensions.

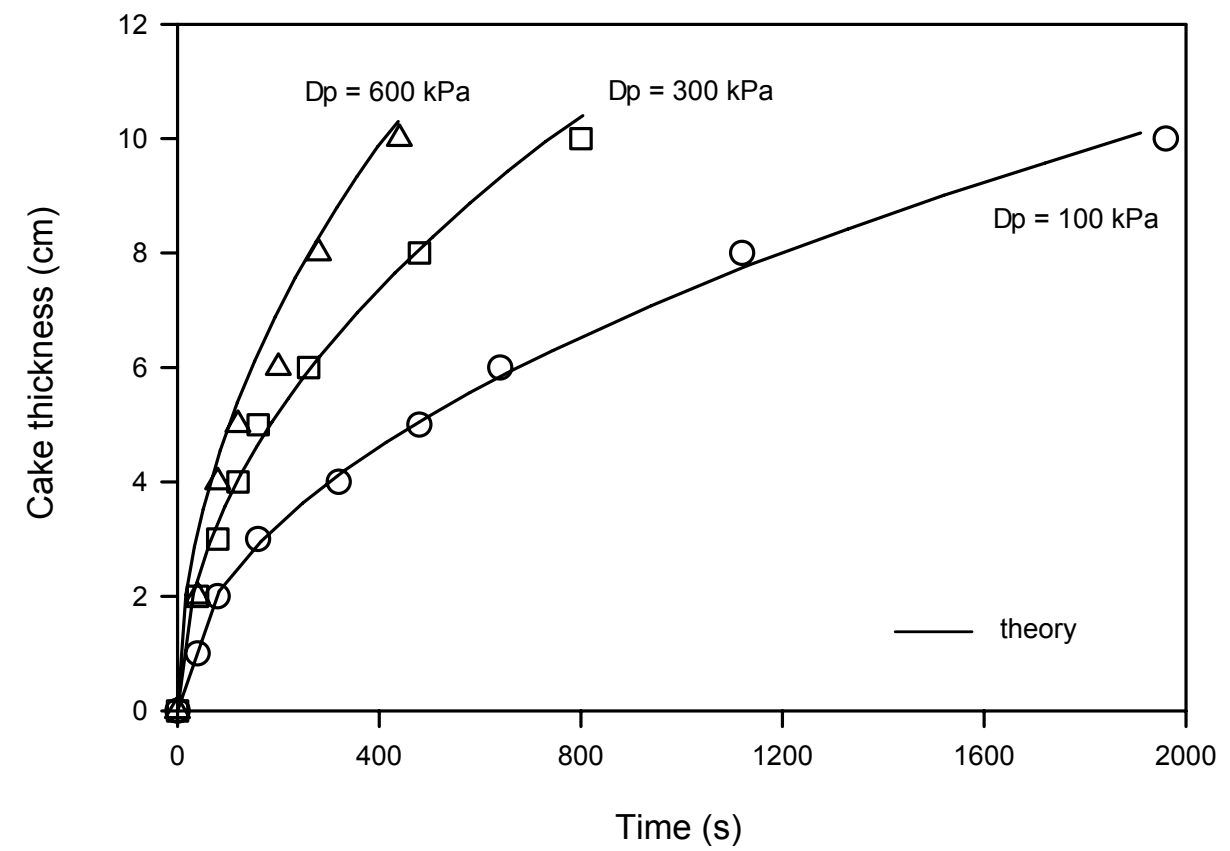

Figure 8: Cake height predictions for the constant pressure filtration of calcite suspensions. 


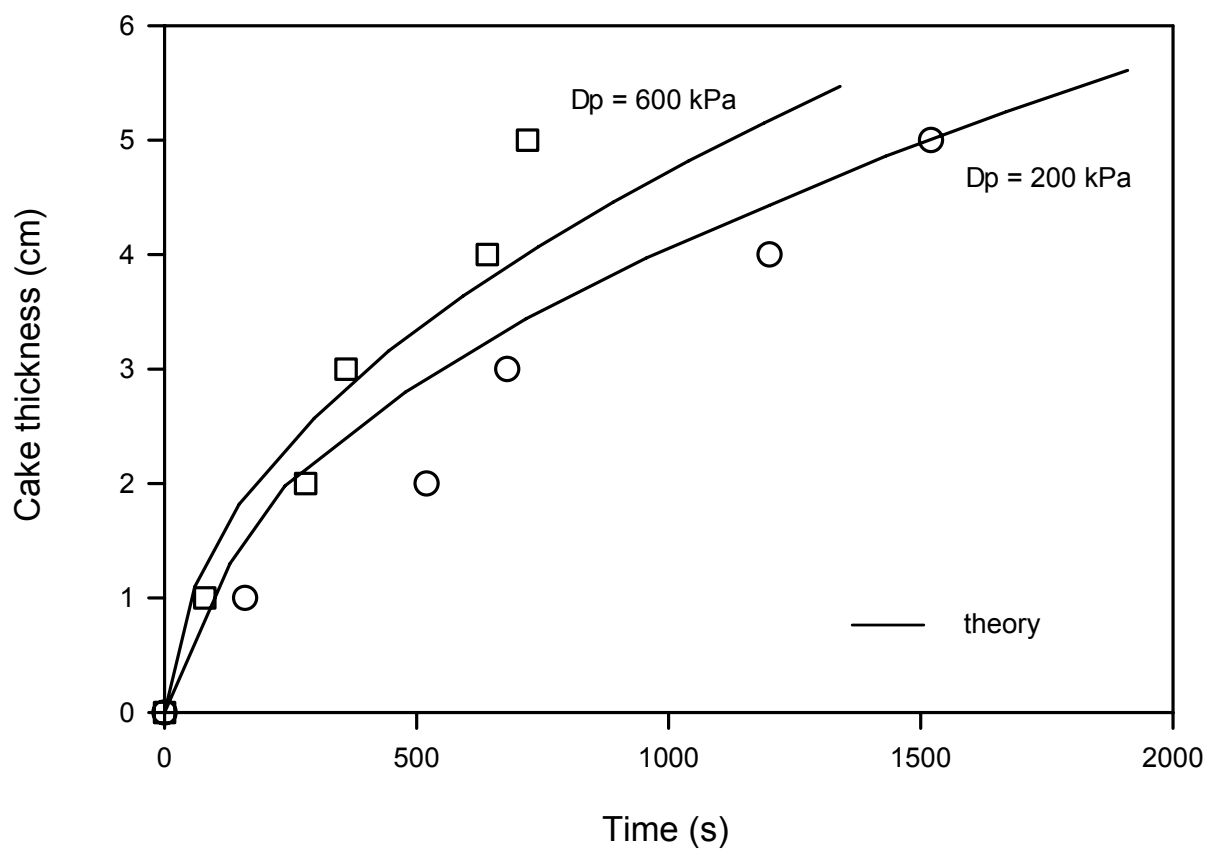

Figure 9: Cake height predictions for the constant pressure filtration of talc suspensions.

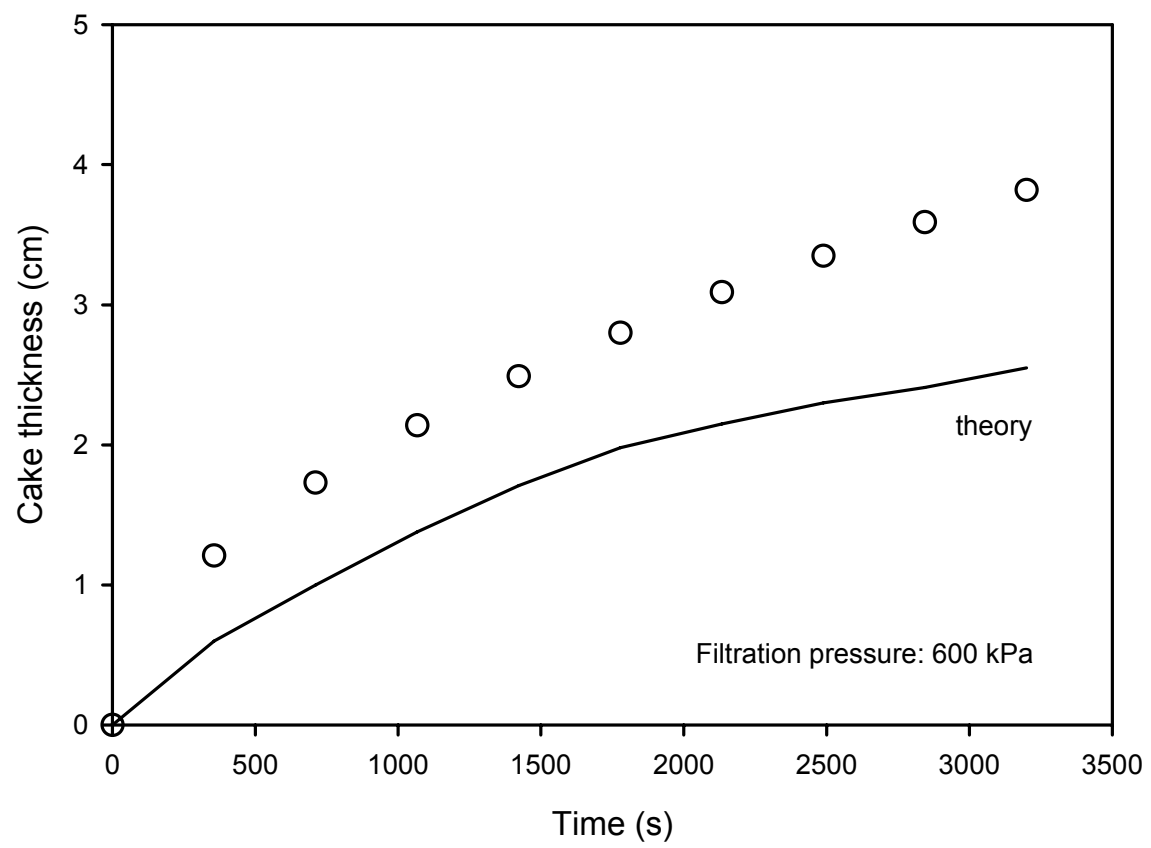

Figure 10: A prediction of cake height vs. time for the constant pressure filtration of a zinc sulphide suspension. 


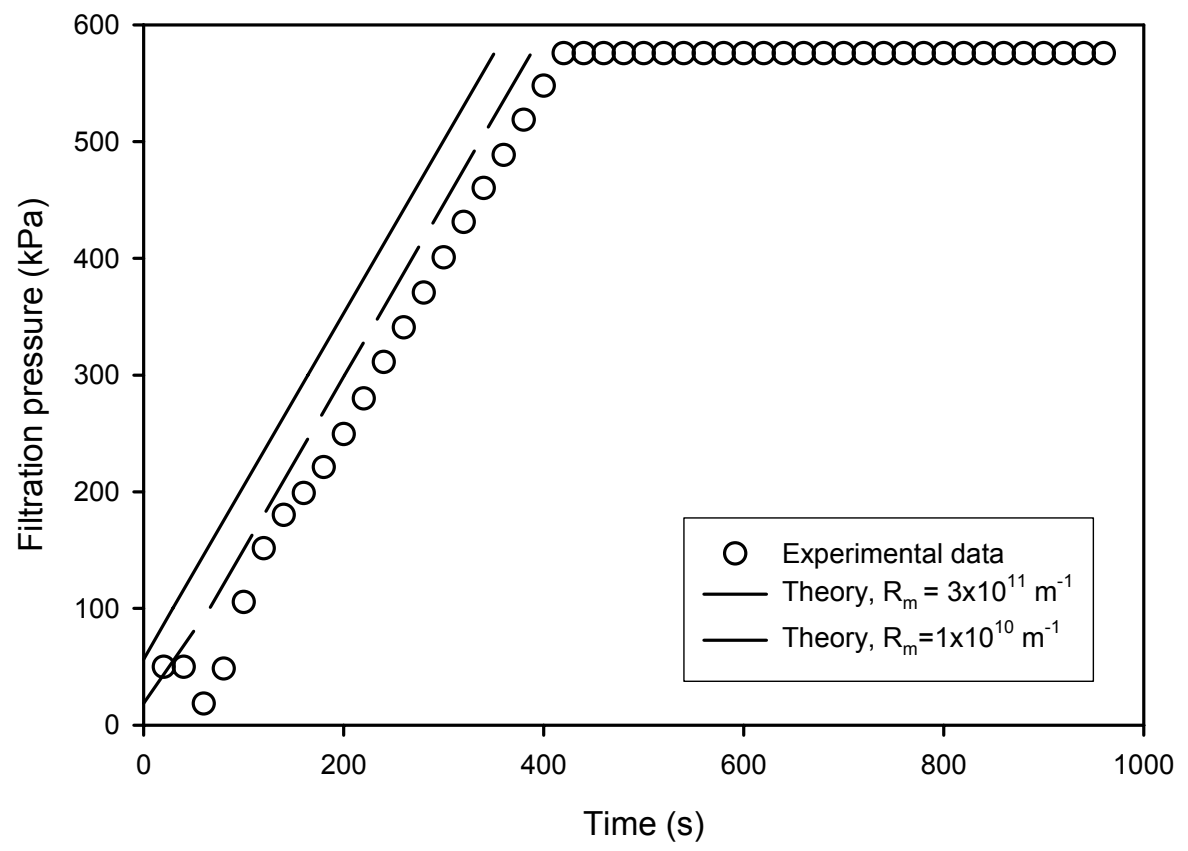

Figure 11: Comparisons of experimental constant flow data and predictions made with scale-up constants derived from constant pressure data. 


\begin{tabular}{|l|c|c|c|c|}
\hline Measured parameter & Calcite & Zinc sulphide $^{*}$ & Talc & Membrane \\
\hline $50 \%$ particle size $(\mu \mathrm{m})$ & 11.3 & $3.5-15^{* *}$ & 8.5 & - \\
Size variance $\left(\mu \mathrm{m}^{2}\right)$ & 213 & $543-5800^{* *}$ & & - \\
Particle shape & Rhomboidal & Oblate ellipsoid & Platelet & - \\
Iso-electric $\mathrm{pH}$ & 9.0 & $2.0^{\dagger}$ & $2.0^{\dagger+}$ & - \\
$\mathrm{pH} \&$ maximum & $10.5 \&-20^{\ddagger}$ & $12.0 \&-50^{\ddagger}$ & $11.0 \&-55^{\ddagger}$ & - \\
$\zeta$-potential $(\mathrm{mV})$ & & & & \\
$10 / 50 / 90 \%$ pore sizes $(\mu \mathrm{m})$ & - & - & - & $0.17 / 0.25 / 0.30$ \\
Permeability $\left(\mathrm{m}^{2}\right)$ & - & - & - & $7.0 \times 10^{-15}$ \\
Thickness $(\mu \mathrm{m})$ & - & - & - & 185 \\
\hline
\end{tabular}

Analar grade $\mathrm{HCl}^{\dagger}$, Acetic acid ${ }^{\dagger \dagger}$ or $\mathrm{NaOH}^{\ddagger}$ used to alter $\mathrm{pH}$

*Dispex added, ${ }^{* \star}$ Dependent on ionic environment

Table 1: Characterisation data for the feed suspensions and Versapor membrane.

\begin{tabular}{|c|c|c|c|c|}
\hline Suspension & $\alpha_{0}\left(\mathrm{~m} \mathrm{~kg}^{-1}\right)$ & $n(-)$ & $e_{0}(-)$ & $b_{1}(-)$ \\
\hline Calcite $^{+}$ & $2.55 \times 10^{9}$ & 0.132 & 2.101 & 0.127 \\
\hline Calcite $^{t+}$ & $1.17 \times 10^{9}$ & 0.198 & 3.415 & 0.322 \\
\hline Talc $^{\text {tr }}$ & $1.82 \times 10^{8}$ & 0.587 & 3.701 & 0.354 \\
\hline Zinc sulphide $^{t}$ & $6.14 \times 10^{9}$ & 0.417 & 1.790 & 0.070 \\
\hline
\end{tabular}

Table 2: Empirical scale-up constants for $10 \%$ v/v calcite, talc and zinc sulphide suspensions (pressures in $\mathrm{Pa}$ ). 